\title{
Monitoring of water stress in peanut using multispectral indices derived from canopy hyperspectral
}

\author{
Tingting Chen ${ }^{1}$, Leidi Wang ${ }^{1}$, Haixia Qi ${ }^{2,4}$, Xinyue Wang ${ }^{1}$, Ruier Zeng ${ }^{1}$, \\ Bingyu Zhu ${ }^{2,4}$, Yubin Lan ${ }^{2,3^{*}}$, Lei Zhang ${ }^{1,2^{*}}$ \\ (1. College of Agriculture, South China Agricultural University, Guangzhou, 510642, China; \\ 2. National Center for International Collaboration Research on Precision Agricultural Aviation Pesticides Spraying Technology (NPAAC), \\ Guangzhou 510642, China; \\ 3. College of Electronic Engineering, South China Agricultural University, Guangzhou, 510642, PR China; \\ 4. College of Engineering, South China Agricultural University, Guangzhou, 510642, PR China)
}

\begin{abstract}
Drought stress was a severe environmental constraint to peanut growth all over the world, and became more and more serious with the global warming context. So, timely and accurate monitoring of water status in peanut is important for farmer to irrigate promptly and acquire higher yield. Our study was conducted to select the most appropriate multispectral indices for water stress monitoring of two peanut cultivars based on canopy spectral reflectance in visible-infrared (VIS) and near infrared (NIR) region. The physiological parameters chlorophyll fluorescence (Fv/Fm), chlorophyll content (SPAD) and leaf relative water content (LRWC) decreased as the drought stress level increased and showed significant relationships between each other. Decreases on the canopy spectral reflectance were observed in both cultivars, especially in NIR region $(720-900 \mathrm{~nm})$ as the leaf water loss was intensified. Six indices (RDVI, TCARI, OSAVI, TCARI/OSAVI, MTVI, and EVI-2) showed higher polynomial relationship $\left(R^{2}>R_{0.05}^{2}, n=93\right)$ with the physiology parameters (Fv/Fm, SPAD and LRWC, respectively) based on the pooled data, which included the two cultivars, three drought stress treatments and the replications. After testing the above six sensitive indices under different drought stress, MTVI was the only multispectral indices, which showed significant curvilinear relationships with the three parameters under different drought stress conditions and might be a useful tool in the development of automatic systems. Our results may provide a non-destructive, simple and real-time method for water status monitoring in peanut production that can assist farmers in timely irrigation.
\end{abstract}

Keywords: Arachis hypogaea L., drought, canopy reflectance, monitor

DOI: $10.33440 /$ j.ijpaa.20200303.104

Citation: Chen T T, Wang L D, Qi H X, Wang X Y, Zeng R E, Zhu B Y, Lan Y B, Zhang L. Monitoring of water stress in peanut using multispectral indices derived from canopy hyperspectral. Int J Precis Agric Aviat, 2020; 3(3): 50-58.

\section{Introduction}

Peanut (Arachis hypogaea L.) is a major oil and food $\operatorname{crop}^{[1]}$; it is cultivated in more than 100 countries and features a world production of 45.22 million tons ${ }^{[2]}$. However, more than $70 \%$ of the peanuts face the drought stress, which affect the peanut production, in the semi-arid tropics ${ }^{[3]}$. With global warming context, drought has become a more acute problem all over the world $^{[4,5]}$.

In order to solve the drought effect on plants growth, many studies have been conducted employing the mechanism of drought

Received data: 2020-07-03 Accepted data: 2020-09-17

Biographies: Tingting Chen, Assistant research fellow, research interests: crop physiology and precision agricultural, Email: chentingting@scau.edu.cn; Leidi Wang, lecturer, research interests: precision agricultural aviation application, Email: wangld@mail.iap.ac.cn; Haixia Qi, associate professor, research interests: precision agricultural aviation application, Email: qihaixia_scau@126.com; Xinyue Wang, Master student, research interests: crop physiology, Email: wangxinyuescau@163.com; Ruier Zeng, Master student, research interests: crop physiology, Email: ruierzeng@126.com; Bingyu Zhu, Master student, research interests: precision agricultural aviation application, Email: zby@stu.scau.edu.cn.

* Corresponding author: Yubin Lan, PhD, Distinguished Professor, Director, research interests: precision agricultural aviation application, Mailing Address: College of Electronic Engineering, South China Agricultural University. Email: ylan@scau.edu.cn; Lei Zhang, PhD, Associate Professor, research interests: crop physiology and precision agricultural, Mailing Address: College of Agriculture, South China Agricultural University. Email: zhanglei@scau.edu.cn. tolerance in plants at physiology ${ }^{[6]}$ and molecular levels ${ }^{[7]}$ or obtaining the water status of plant and irrigate timely ${ }^{[8]}$. Many important morphophysiological parameters, such as chlorophyll fluorescence, chlorophyll content and leaf relative water content (LRWC) are the first reaction to drought stress ${ }^{[9-11]}$. Chlorophyll content and fluorescence is the most popular techniques in plant physiology because of the ease with which the user can gain detailed information on the state of photosystem II (PSII) at a relatively low cost and is extremely suitable for screening the physiological parameters of plants ${ }^{[10,12]}$. However, the traditional measurement of these parameters based on plant sampling technique were destructive, time-consuming and inappropriate for real-time monitoring of the water status of plant. Additionally, the traditional method might provide information on a single leaf irrespective of age and positions of leaves ${ }^{[13]}$. Therefore, measurements of these parameters based on single leaf cannot reflect the entire canopy accurately, and the drought was associated with various subjects like agriculture, meteorology and plant physiology and it is an interaction field for natural systems ${ }^{[14]}$. Therefore, it is important for crop managers to obtain a practical method that timely provides precise information about the above information for reflecting water status of plants to guide the irrigate production on time.

Hyperspectral reflectance technique has been demonstrated an valuable and powerful methods for assessing the abiotic stress ${ }^{[15]}$ and remote sensing-based drought indices have been widely used 
for quantification of plant water status. To date, many studies have developed drought indices to characterize drought conditions, such as photochemical reflectance index $(\mathrm{PRI})^{[16]}$, renormalized difference vegetation index $(\mathrm{RDVI})^{[17]}$, normalized difference vegetation index(NDVI) ${ }^{[18]}$, transformed chlorophyll absorption in reflectance index(TCARI) ${ }^{[19]}$, optimized soil adjusted vegetation index $(\mathrm{OSAVI})^{[19]}$, modified transformed vegetation index $(\mathrm{MTVI})^{[20]}$, and enhanced vegetation index-2 (EVI-2) ${ }^{[21]}$ et al.. Until now, many researches have constructed the drought indices and summarized the disadvantages and advantages of these indices based on the application and sensitive region ${ }^{[22]}$. However, the indices may vary seriously as the physical environment (climate, soil and crop) varies from region to region and each crop responds to drought stress differently. To the best of our knowledge, there are few studies that are conducted to monitoring the water status of peanut plant accurately through remote sensing under drought stress. Therefore, this study will compare the performance of 20 multispectral indices to determine which are most appropriate for monitoring agricultural drought stress in South China. The aim of this study is to (1) compare the chlorophyll fluorescence, SPAD values and leaf relative water content of two peanut cultivars under different drought stress and their relationships, (2) analyze the change of canopy spectral reflectance of the two peanut cultivar under different drought stress, and (3) select and test the best multispectral indices for monitoring the LRWC, SPAD and Fv/Fm, which could monitor the water status of peanut plants when subjected to different drought stress conditions.

\section{Materials and methods}

\subsection{Experiment design}

The experiment was conducted under a rain exclusion shelter during the growth seasons of 2018 at the Experimental Research Farm, College of Agriculture, South China Agricultural University, Guangzhou, China (location: $23^{\circ} 09^{\prime} \mathrm{N}, 113^{\circ} 22^{\prime} \mathrm{E}$; altitude: $11 \mathrm{~m}$ ). Cultivars Yuhua 9326 and Zhonghua 4 were chosen, as they are widely grown in China. Uniform seeds of both cultivars were surface-sterilized by dipping in $0.5 \%$ hypochlorite solution for $20 \mathrm{~min}$ and then rinsing thoroughly with distilled water followed by drying before sowing. Each pot was filled with $10 \mathrm{~kg}$ air-dried, sieved and uniformly mixed soil. $0.8 \mathrm{~g} \mathrm{~N}, 0.5 \mathrm{~g} \mathrm{P}_{2} \mathrm{O}_{5}$ and $1.2 \mathrm{~g}$ $\mathrm{K}_{2} \mathrm{O}$ were applied for each pot. Two seeds were sowed each pot. Each pot was irrigated to $(75 \pm 5) \%$ field capacity $(\mathrm{FC})$. Other weeds and pests were controlled according to local agronomic practices.

When the peanut plants begin flowering (40 days after planting), three drought stress treatments, including well-watered, mild drought stress and severe drought stress corresponding to $(75 \pm 5) \% \mathrm{FC},(55 \pm 5) \% \mathrm{FC}$, and $(35 \pm 5) \% \mathrm{FC}$, respectively, were applied to each cultivar. For drought stress imposition, the irrigation to pots was withhold until the soil FC reached to $(55 \pm 5) \% \mathrm{FC}$, and $(35 \pm 5) \% \mathrm{FC}$ for mild and severe drought stress. Then drought stress treatments were maintained for 7days. Soil FC for the specific drought levels was maintaining by weighting pots and then compensating on a daily basis.

\subsection{Data acquisition}

\subsubsection{Physiological parameters measurement}

At the last day of the drought experiment, chlorophyll fluorescence was measured using a portable chlorophyll fluorometer (PAM-2500, Walz, Germany). Three readings were taken on functional leaves in each treatment randomly. The parameters measured were: maximum fluorescence $(\mathrm{Fm})$, basal fluorescence (Fo), variable fluorescence yield (Fv) of dark-adapted leaves (measured at night); The calculated parameters were Maximum Quantum Yield of PSII Photochemistry (Fv/Fm) The relative chlorophyll content by SPAD (Soil Plant Analysis Development) chlorophyll reading (SPAD-502, Konica Minolta Optics Inc., Japan) were measured the same leaves as the chlorophyll fluorometer.

Leaf relative water content was determined according to the methods of Barrs and Weatherly (1962) as LRWC $=(\mathrm{FW}-\mathrm{DW}) /$ (TW-DW), where FW is fresh leaf weight, DW is dry weight and TW is turgid weight after $24 \mathrm{~h}$ floating in distilled water at $4^{\circ} \mathrm{C}$ in darkness $^{[23]}$.

\subsubsection{Canopy reflectance measurements}

In parallel with the chlorophyll fluorescence measurements, canopy reflectance spectra were measured according to the methods of Chen et al. (2018) ${ }^{[24]}$ by using a FieldSpec UV/VNIR spectraradiometer (ASD Inc., Boulder, Colorado, USA) over the $325-1075 \mathrm{~nm}$ wavelength range at $3 \mathrm{~nm}$ intervals. The $3 \mathrm{~nm}$ intervals are automatically interpolated to $1 \mathrm{~nm}$ intervals by this instrument. The field of view is $25^{\circ}$. Measurements were taken on clear, sunny days between 10:00h and 14:00h (Beijing time). A panel radiance measurement was taken to optimize the instrument before and after every plot measurement. The adaxial surfaces of the samples were measured five times to generate an average spectral reflectance curve. The generated data were interpolated using ASD ViewSpec Pro software to obtain reflectance values at $1 \mathrm{~nm}$ intervals.

\subsection{Data analysis}

The raw DN values recorded from the field were converted to reflectance values using the ASD ViewSpecPro software ((ASD), 2002). From a physiological perspective, the changes in chlorophyll content, chlorophyll fluorescence, and leaf relative water content on the leaf surface induced by drought stress are responsible for the detected spectral changes. Therefore, to utilize these important features potentially sensitive to changes, a total of 20 multispectral indices extracted from the literature (Table 1) were subjected to linear, polynomial, exponential and power regression analysis in order to quantify their relationship with the three physiological parameters using the data $(n=86)$.

Person correlation coefficient (r) between the three physiological parameters was calculated under different drought stress conditions ( $n=31$ ), and the $R^{2}$ and the equation were used to evaluate fitness between the physiological parameters and multispectral indices under different drought stress conditions. The graphs were generated using OriginPro 2018.

\section{Results and discussion}

\subsection{Effect of drought stress on leaf relative water content, SPAD values and $\mathrm{Fv} / \mathrm{Fm}$ of peanut leaves}

Osmotic adjustment is an important mechanism of crop drought resistance. Under drought stress, cells maintain a certain swell pressure by accumulating inorganic molecules and soluble organic matter, so that physiological processes such as cell growth, stomatal movement and photosynthesis are normal; however, osmotic adjustment is lost during severe drought (Blum, 1989; Mccree, 1986). According to our results, drought stress significantly decreased peanut leaves LRWC, Fv/Fm and SPAD of both cultivars, with no significant difference between cultivars Yuhua 9326 and Zhonghua 4 (Figure 1), which in turn less light was reflected in the drought stress leaves ${ }^{[33]}$ and might explain the change of canopy reflectance under drought stress in our study. 
Table 1 Full name and abbreviation of the multispectral indices used in this study

\begin{tabular}{|c|c|c|}
\hline Full name of multispectral indices & Formula & Citation \\
\hline Photochemical reflectance index (PRI) & $(\mathrm{R} 531-\mathrm{R} 570) /(\mathrm{R} 531+\mathrm{R} 570)$ & Gamon (1992) ${ }^{[16]}$ \\
\hline Normalized difference vegetation index (NDVI) & $(\mathrm{R} 800-\mathrm{R} 670) /(\mathrm{R} 800+\mathrm{R} 670)$ & Rouse et al. $(1973)^{[25]}$ \\
\hline Renormalized difference vegetation index (RDVI) & $(\mathrm{R} 800-\mathrm{R} 670) /(\mathrm{R} 800+\mathrm{R} 670)^{0.5}$ & Rougean and Breon, $(1995)^{[26]}$ \\
\hline Transformed chlorophyll absorption in reflectance index (TCARI) & $3 *[(\mathrm{R} 700-\mathrm{R} 670)-2(\mathrm{R} 700-\mathrm{R} 550) *(\mathrm{R} 700 / \mathrm{R} 670)]$ & Haboudane et al $(2002)^{[19]}$ \\
\hline Optimized soil adjusted vegetation index (OSAVI) & $((1+0.16)(\mathrm{R} 800-\mathrm{R} 670)) /((\mathrm{R} 800+\mathrm{R} 670)+0.16)$ & Haboudane et al $(2002)^{[19]}$ \\
\hline Green chlorophyll index (GCI) & $(\mathrm{R} 800 / \mathrm{R} 550)-1$ & Wu et al $(2012)^{[28]}$ \\
\hline Structure insensitive pigment index (SIPI) & $(\mathrm{R} 800-\mathrm{R} 445) /(\mathrm{R} 800-\mathrm{R} 680)$ & Penuelas et al. $(1995)^{[29]}$ \\
\hline Red edge model (REM) & $(\mathrm{R} 800 / \mathrm{R} 700)-1$ & Gitelson et al. $(2005)^{[30]}$ \\
\hline TCARI/OSAVI & $\begin{array}{l}3 *[(\mathrm{R} 700-\mathrm{R} 670)-2(\mathrm{R} 700-\mathrm{R} 550) *(\mathrm{R} 700 / \mathrm{R} 670)] / \\
((1+0.16)(\mathrm{R} 800-\mathrm{R} 670)) /((\mathrm{R} 800+\mathrm{R} 670)+0.16)\end{array}$ & Haboudane et al. $(2002)^{[19]}$ \\
\hline Pigment specific simple ratio-a (PSSR-a) & R800/R680 & Blackburn $(1998)^{[31]}$ \\
\hline Pigment specific simple ratio-c (PSSR-c) & $\mathrm{R} 800 / \mathrm{R} 470$ & Blackburn $(1998)^{[31]}$ \\
\hline Pigment specific normalized difference-a (PSND-a) & $(\mathrm{R} 800-\mathrm{R} 680) /(\mathrm{R} 800+\mathrm{R} 680)$ & Blackburn $(1998)^{[31]}$ \\
\hline Pigment specific normalized difference-b (PSND-b) & $(\mathrm{R} 800-\mathrm{R} 635) /(\mathrm{R} 800+\mathrm{R} 635)$ & Blackburn $(1998)^{[31]}$ \\
\hline Pigment specific normalized difference-c (PSND-c) & $(\mathrm{R} 800-\mathrm{R} 470) /(\mathrm{R} 800+\mathrm{R} 680)$ & Blackburn $(1998)^{[31]}$ \\
\hline Normalized phaeophytinization index (NPQ) & $(\mathrm{R} 415-\mathrm{R} 534) /(\mathrm{R} 415+\mathrm{R} 435)$ & Penuelas et al. $(1995)^{[29]}$ \\
\hline Modified transformed vegetation index (MTVI) & $1.2 *[1.2 *(\mathrm{R} 800-\mathrm{R} 550)-2.5 *(\mathrm{R} 670-550)]$ & Zhen et al. (2019) ${ }^{[20]}$ \\
\hline Enhanced vegetation index-2 (EVI-2) & $2.5 *[(\mathrm{R} 800-\mathrm{R} 660) /(1+\mathrm{R} 800+2.4 * \mathrm{R} 660)]$ & Mondal et al. $(2011)^{[21]}$ \\
\hline Carter index 2 (CTR-2) & $\mathrm{R} 695 / \mathrm{R} 760$ & Carter $(1994)^{[32]}$ \\
\hline
\end{tabular}
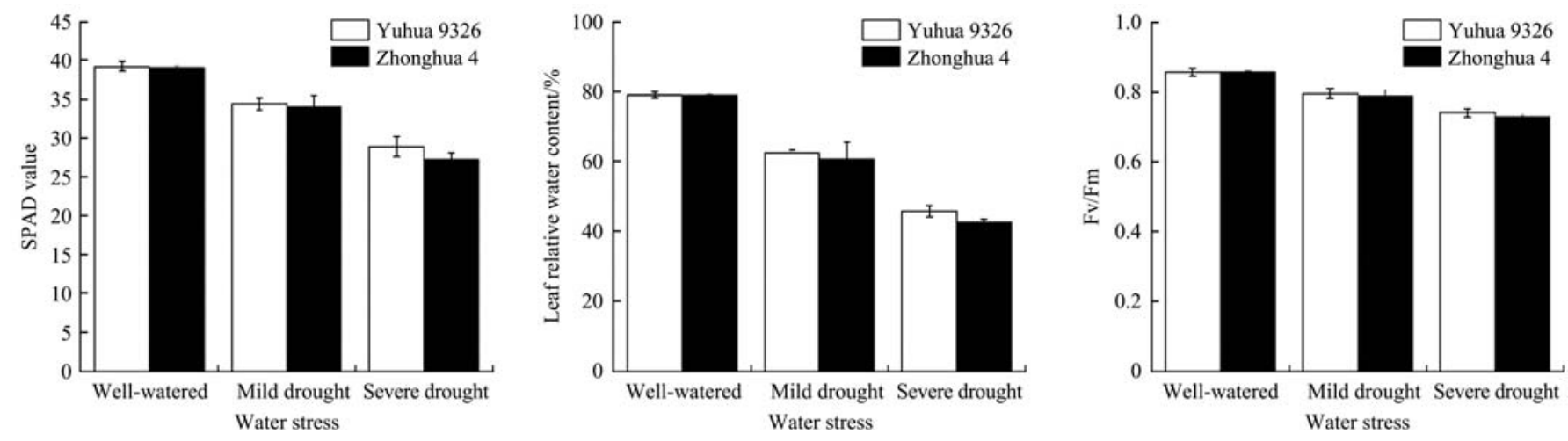

Figure 1 Effects of drought stress on physiological parameters in two cultivars at the seedling stage

We also analyse the relationship between the above three parameters under different drought stress treatments (Figure 2). There was significant relationship between the SPAD values and $\mathrm{Fv} / \mathrm{Fm}$, leaf relative water content under different drought stress, and the strongest relationship was found under mild drought stress $\left(R^{2}=0.9422\right)$ and well-watered $\left(R^{2}=0.8898\right)$, respectively. In addition, the $\mathrm{Fv} / \mathrm{Fm}$ and leaf relative water content showed a stronger relationship under different drought stress and the strongest relationship $\left(R^{2}=0.9048\right)$ between $\mathrm{Fv} / \mathrm{Fm}$ and leaf relative water content was found in the mild drought stress. The above results indicated that the leaf relative water content, SPAD values and $\mathrm{Fv} / \mathrm{Fm}$ were significantly affected by the drought stress and have the strong relationship with each other, whichin turn affect the radiation absorption and reflection at different drought stress, so that the derivative relationships between the reflectance and the physiological parameters (SPAD, LRWC and Fv/Fm) can be applied to detect the leaf water status of the peanuts plants under drought stress. However, some researches have concluded that there is a weak relationship between Pn and plant growth under drought stress, where the drought stress affected the plant growth seriously ${ }^{[34]}$. The differences might be related to crop differences in mechanisms of adaption to drought stress, where some crops can adapt to drought stress through reducing plant growth ${ }^{[35]}$. However, other crops could maintain higher growth rate ${ }^{[36]}$.

3.2 Changes of canopy reflectance under different drought stress

The dynamic change of mean canopy reflectance with different drought stress at the seedling stages of both cultivars are showed in Figure 3. As the drought stress level increased, the canopy reflectance decreased significantly in both cultivars, especially in NIR region $(720-900 \mathrm{~nm})$. And two peanut cultivars showed the same trend under different drought stress. In the near infrared regions $(700-900 \mathrm{~nm})$, which the magnitude reflectance is related to the structural discontinuities encountered in the leaf and the absorption characteristics of water and other compounds, respectively ${ }^{[37]}$, the curves of spectral reflectance for the three drought stress were clearly separated in both cultivars, whereas the spectral reflectance of the well-watered treatments were very close together between two cultivars. However, in the visible-infrared regions (VIS, 400-700 nm), in which is related to the leaf chlorophyll content ${ }^{[38]}$, the canopy spectra reflectance values of drought stress plants presented an insignificant decrease and was accompanied by a slight decrease as drought stress increased. These results also reveals that it is 
possible to capture the effect of drought stress on the chlorophyll content, LRWC and $\mathrm{Fv} / \mathrm{Fm}$ of peanut plants in terms of their spectral signature in these two parts of the spectral reflectance, which is consistent with Zygielbaum et al. (2009) ${ }^{[39]}$, who pointed out that the changes in canopy reflectance affected by drought
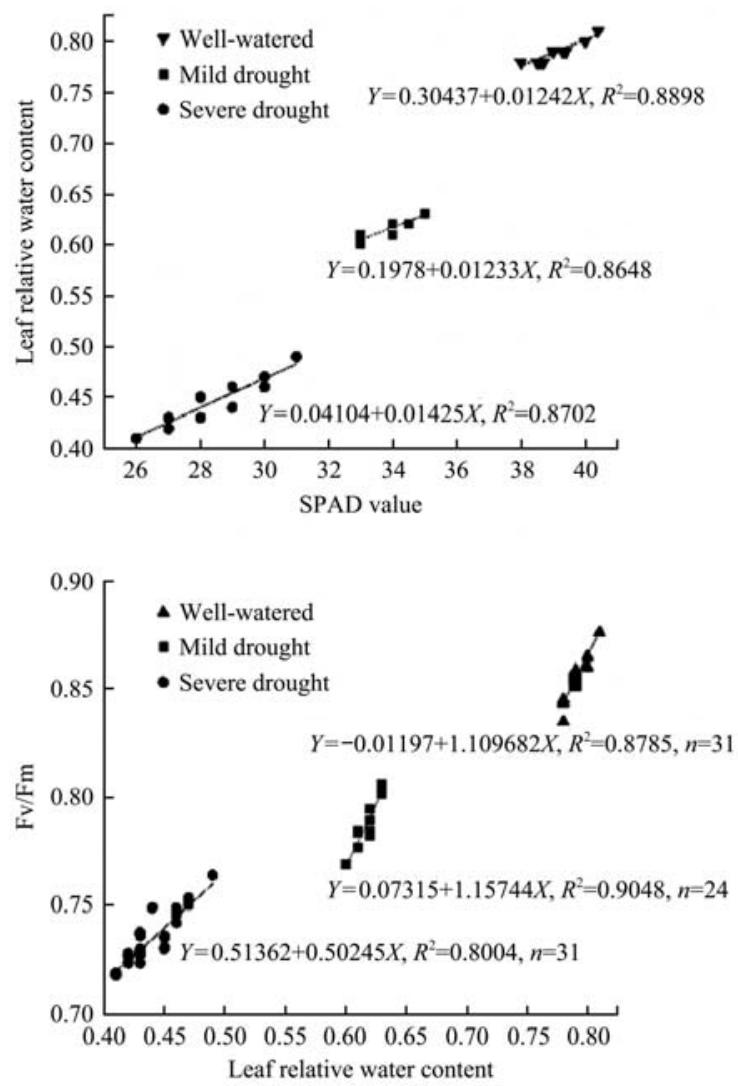

stress can be detected. Therefore, we continued to explore the potential of several multispectral indices, which combine the VIS and NIR regions, as a proxy tool for effective, non-destructively monitoring the water stress of peanut under different drought stress in the field.

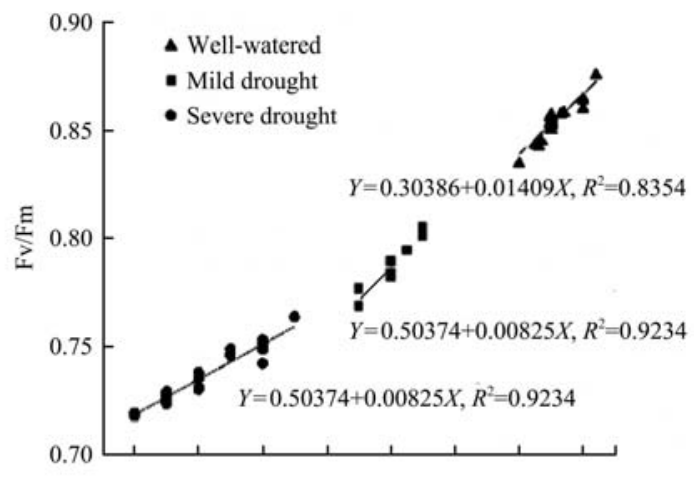

Figure 2 Pearson's correlation matrix of Fv/Fm, SPAD and LRWC across two cultivars under different drought stress.

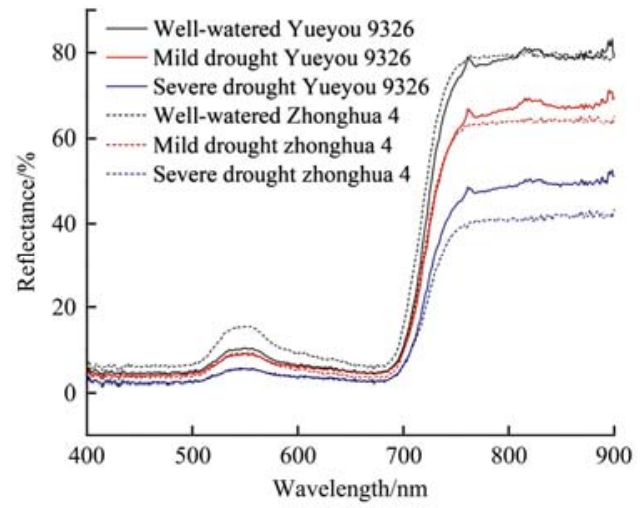

Figure 3 Effects of drought stress on the canopy spectral reflectance in two peanut cultivars in the range between 400 and $900 \mathrm{~nm}$

\subsection{Relationships between published indices and physiology parameters}

Twenty published spectral reflectance indices which are sensitive to the change of leaf chlorophyll content, leaf structure, were regressed with the SPAD, LRWC and Fv/Fm. The two cultivars, three drought stress treatments and the replications were pooled together to assess the relationship between the physiology parameters and indices based on the determination coefficient $\left(R^{2}\right)$ and equation (Table 2).

Based on the $R^{2}$ values, six indices (RDVI, TCARI, OSAVI, TCARI/OSAVI, MTVI, and EVI-2) from the 20 indices, which showed the higher $R^{2}$ between the physiology parameters and multispectral indices, were selected to monitoring the water status of peanut. And the polynomial equation were the best models describing the relationships between multispectral indices and SPAD, Fv/Fm, and LRWC, with the exception of the MTVI in the SPAD. The reason might be that the two cultivars exhibited different response to different drought stress. The values of $R^{2}$ for these relationships ranged from 0.34 to 0.93 , from 0.34 to 0.92 and from 0.34 to 0.90 for $\mathrm{Fv} / \mathrm{Fm}, \mathrm{SPAD}$ and LRWC, respectively. The best multispectral indices for monitoring peanut physiology parameters, which were used for reflecting the status of drought stress in peanut, were MTVI $\left(R^{2}=0.93,0.92,0.90\right)$ in our study. Most of the sensitive multispectral indices (RDVI, TCARI, OSAVI, TCARI/OSAVI and EVI-2) selected for monitoring the water stress are only based on NIR region. However, the best multispectral indices MTVI which are based on VIS and NIR wavelength showed the strongest relationship with Fv/Fm, SPAD and LRWC, which indicate that the multispectral indices associated with chlorophyll content and leaf structure could be used as an rapid and non-destructive tools for monitoring the water stress of peanut under different drought stress. These results also suggested that wavelengths in the VIS and NIR ranges that combined together may offer a considerable potential for monitoring water stress of peanut crops under drought stress. The reason might be related the fact that the response of peanut plants to drought stress in the VIS and NIR range is possibly associated with a drought stress induced decline in the concentration of chlorophyll content and leaf 
structure, respectively ${ }^{[13]}$. However, the response of plants measured in the NIR ranges may be affected indirectly by drought stress through changes in the leaf structural and scattering at the canopy scales. Although the multispectral indices (RDVI, TCARI,
OSAVI, TCARI/OSAVI and EVI-2) based on NIR regions, which considered as proxies of chlorophyll content, biomass accumulation and plant water status under stressed conditions ${ }^{[40 ; 41]}$, showed weak relationships with Fv/Fm, SPAD and LRWC in our study.

Table 2 The best equations and determination coefficients of the relationships across all data $(n=86)$ between multispectral indices based on the canopy spectral reflectance and the Fv/Fm, SPAD and LRWC. $n=93, R^{2}{ }_{0.05}=0.21$

\begin{tabular}{|c|c|c|c|c|c|c|}
\hline \multirow{2}{*}{ Indices } & \multicolumn{2}{|l|}{$\mathrm{Fv} / \mathrm{Fm}$} & \multicolumn{2}{|l|}{ SPAD } & \multicolumn{2}{|l|}{ LRWC } \\
\hline & Equations & $R^{2}$ & Equations & $R^{2}$ & Equations & $R^{2}$ \\
\hline PRI & $y=1.1309 x^{2}-1.8795 x+0.7342$ & 0.04 & $y=0.0001 x^{2}-0.008 x+0.1037$ & 0.03 & $y=0.1245 x^{2}-0.1808 x+0.0191$ & 0.03 \\
\hline NDVI & $y=-4.3647 x^{2}+6.5424 x-1.7886$ & 0.07 & $y=-0.0007 x^{2}+0.0419 x+0.0322$ & 0.07 & $y=-0.4462 x^{2}+0.4061 x+0.5717$ & 0.07 \\
\hline RDVI & $y=-11.278 x^{2}+19.563 x-7.6773$ & 0.86 & $y=-0.0008 x^{2}+0.0734 x-0.796$ & 0.86 & $y=-1.2365 x^{2}+2.0776 x-0.0674$ & 0.82 \\
\hline TCARI & $y=1.7449 x^{2}-1.7248 x+0.4254$ & 0.41 & $y=0.0005 x^{2}-0.0237 x+0.3503$ & 0.41 & $y=0.2566 x^{2}+0.0474 x+0.0285$ & 0.4 \\
\hline OSAVI & $y=-9.538 x^{2}+15.885 x-5.7565$ & 0.5 & $y=-0.0009 x^{2}+0.071 x-0.483$ & 0.51 & $y=-1.0165 x^{2}+1.4937 x+0.3057$ & 0.45 \\
\hline MCARI & $y=5.6306 x^{2}-8.4709 x+3.128$ & 0.04 & $y=0.0007 x^{2}-0.0447 x+0.609$ & 0.04 & $y=0.3506 x^{2}-0.2686 x-0.0084$ & 0.03 \\
\hline GCI & $y=-63.336 x^{2}+83.055 x-18.855$ & 0.11 & $y=-0.0139 x^{2}+0.7398 x-1.7802$ & 0.11 & $y=11.159 \mathrm{e}^{-0.888 x}$ & 0.11 \\
\hline SIPI & $y=1.0526 \mathrm{e}^{-0.056 x}$ & 0.06 & $y=1.0278 \mathrm{e}^{-6 \mathrm{E}-04 x}$ & 0.05 & $y=-0.0398 x^{2}+0.0301 x+1.0047$ & 0.05 \\
\hline REM & $y=-126.84 x^{2}+193.67 x-67.091$ & 0.04 & $y=-0.0186 x^{2}+1.1567 x-11.077$ & 0.04 & $y=-10.401 x^{2}+10.031 x+4.3807$ & 0.03 \\
\hline TCARI/OSAVI & $y=3.534 x^{2}-4.4992 x+1.5302$ & 0.34 & $y=0.0008 x^{2}-0.0396 x+0.6324$ & 0.34 & $y=0.4766 x^{2}-0.1974 x+0.1256$ & 0.34 \\
\hline PSND-b & $y=-4.1243 x^{2}+6.4178 x-1.6223$ & 0.04 & $y=-0.0006 x^{2}+0.0395 x+0.2416$ & 0.05 & $y=-0.3926 x^{2}+0.429 x+0.7557$ & 0.03 \\
\hline PSND-c & $y=-5.1189 x^{2}+8.561 x-2.7615$ & 0.15 & $y=-0.0004 x^{2}+0.0216 x+0.5758$ & 0.09 & $y=-0.1501 x^{2}+0.1032 x+0.8842$ & 0.09 \\
\hline PSSR-a & $y=-217.27 x^{2}+298.22 x-80.448$ & 0.09 & $y=-0.0561 x^{2}+3.2535 x-25.777$ & 0.1 & $y=-12.323 x^{2}-1.2242 x+24.483$ & 0.09 \\
\hline PSSR-b & $y=-345.27 x^{2}+515.62 x-175.09$ & 0.08 & $y=-0.0573 x^{2}+3.4748 x-34.94$ & 0.09 & $y=-21.506 x^{2}+14.468 x+15.439$ & 0.08 \\
\hline PSSR-c & $y=138.93 \mathrm{e}^{-2.573 x}$ & 0.11 & $y=-0.0904 x^{2}+5.4252 x-58.334$ & 0.11 & $y=31.523 \mathrm{e}^{-0.909 x}$ & 0.11 \\
\hline NPQ & $y=-93.733 x^{2}+153.92 x-63.181$ & 0.08 & $y=0.0001 x^{2}-0.008 x+0.1037$ & 0.03 & $y=-8.6943 x^{2}+12.334 x-4.4158$ & 0.06 \\
\hline MTVI & $y=-16.827 x^{2}+31.199 x-13.191$ & 0.93 & $y=1.5962 \ln (x)-4.6735$ & 0.92 & $y=-1.83 x^{2}+3.7737 x-0.6608$ & 0.9 \\
\hline EVI-2 & $y=-17.896 x^{2}+30.678 x-12.184$ & 0.84 & $y=-0.0014 x^{2}+0.1188 x-1.5228$ & 0.83 & $y=-1.9497 x^{2}+3.1564 x-0.316$ & 0.8 \\
\hline CTR-2 & $y=0.0323 \mathrm{e}^{1.4069 x}$ & 0.04 & $y=0.06 \mathrm{e}^{0.0147 x}$ & 0.04 & $y=0.072 \mathrm{e}^{0.5116 x}$ & 0.04 \\
\hline
\end{tabular}

Note: LRWC: leaf relative water content; $R^{2}$ : determination coefficient.
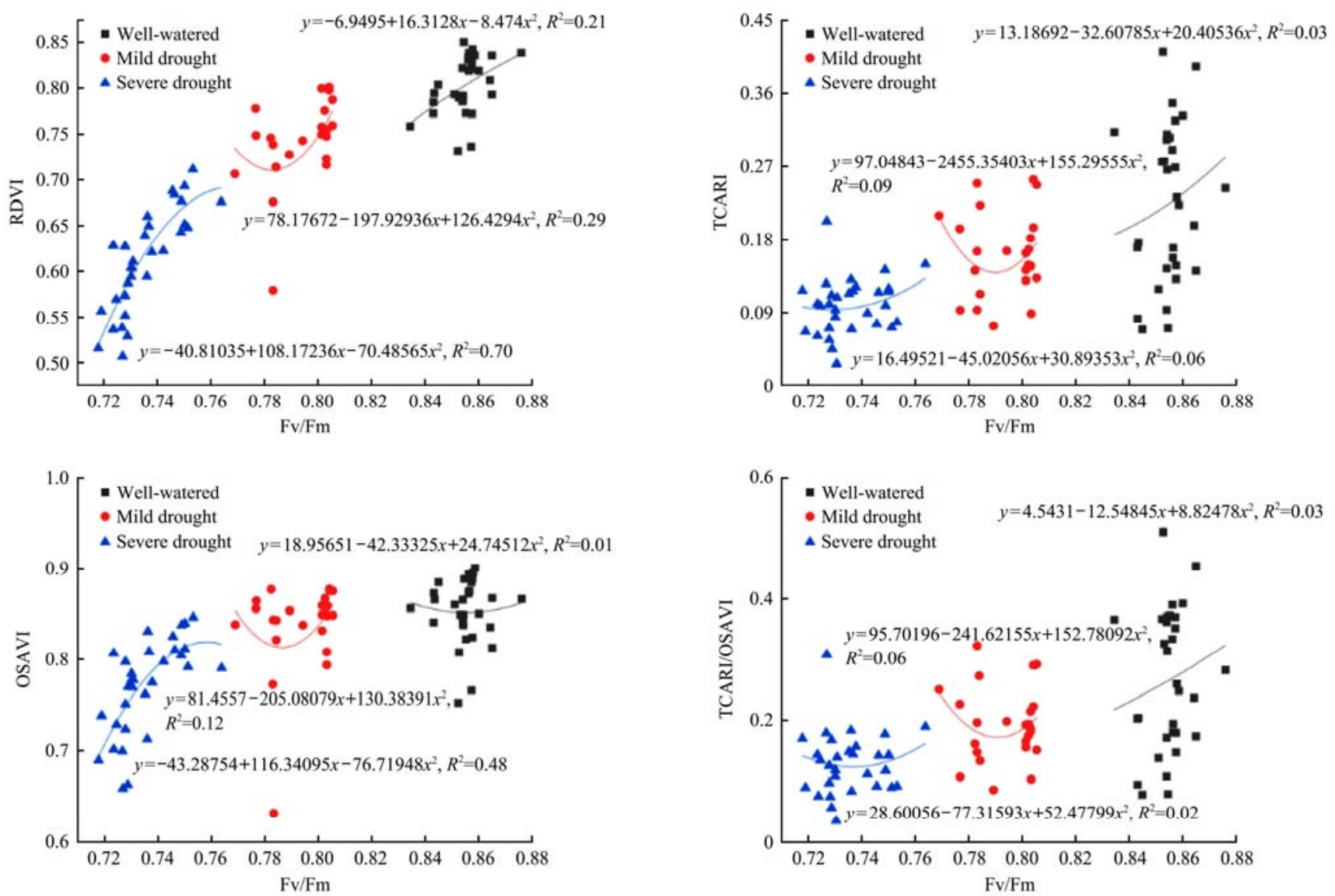

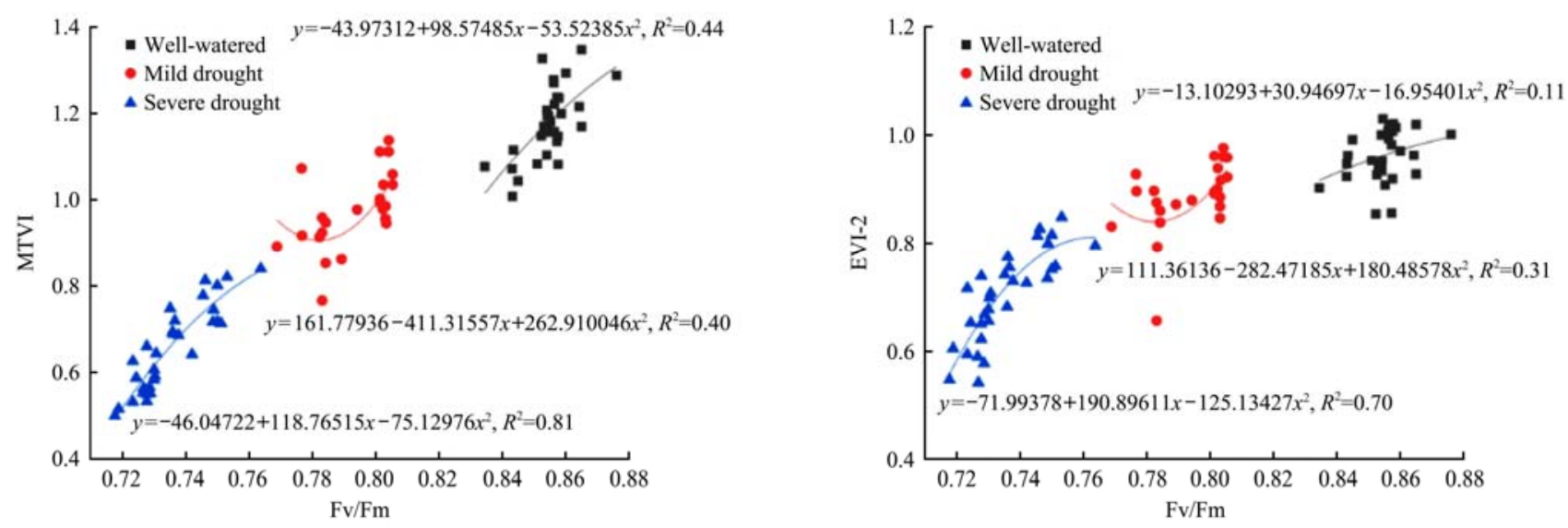

a. Fv/Fm
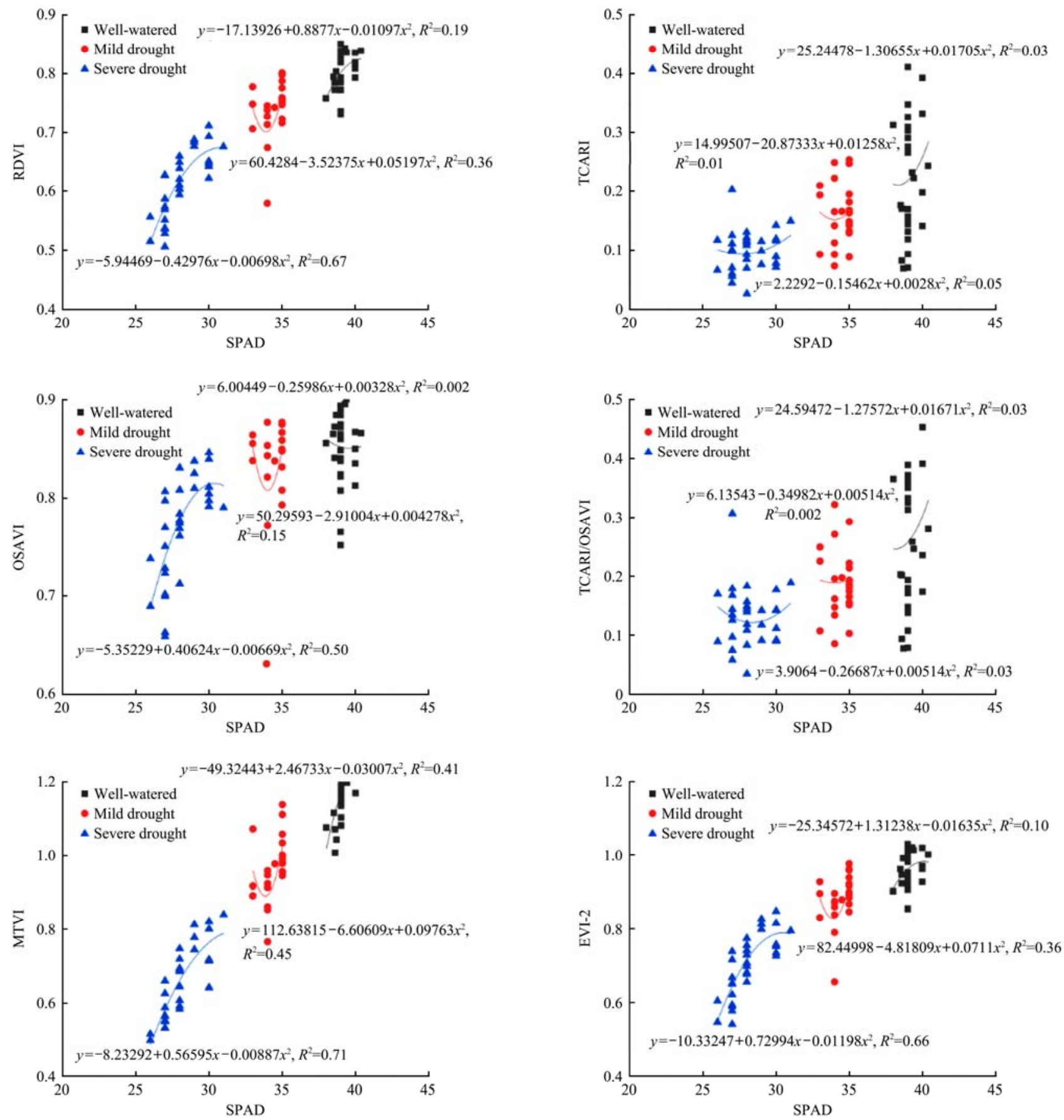

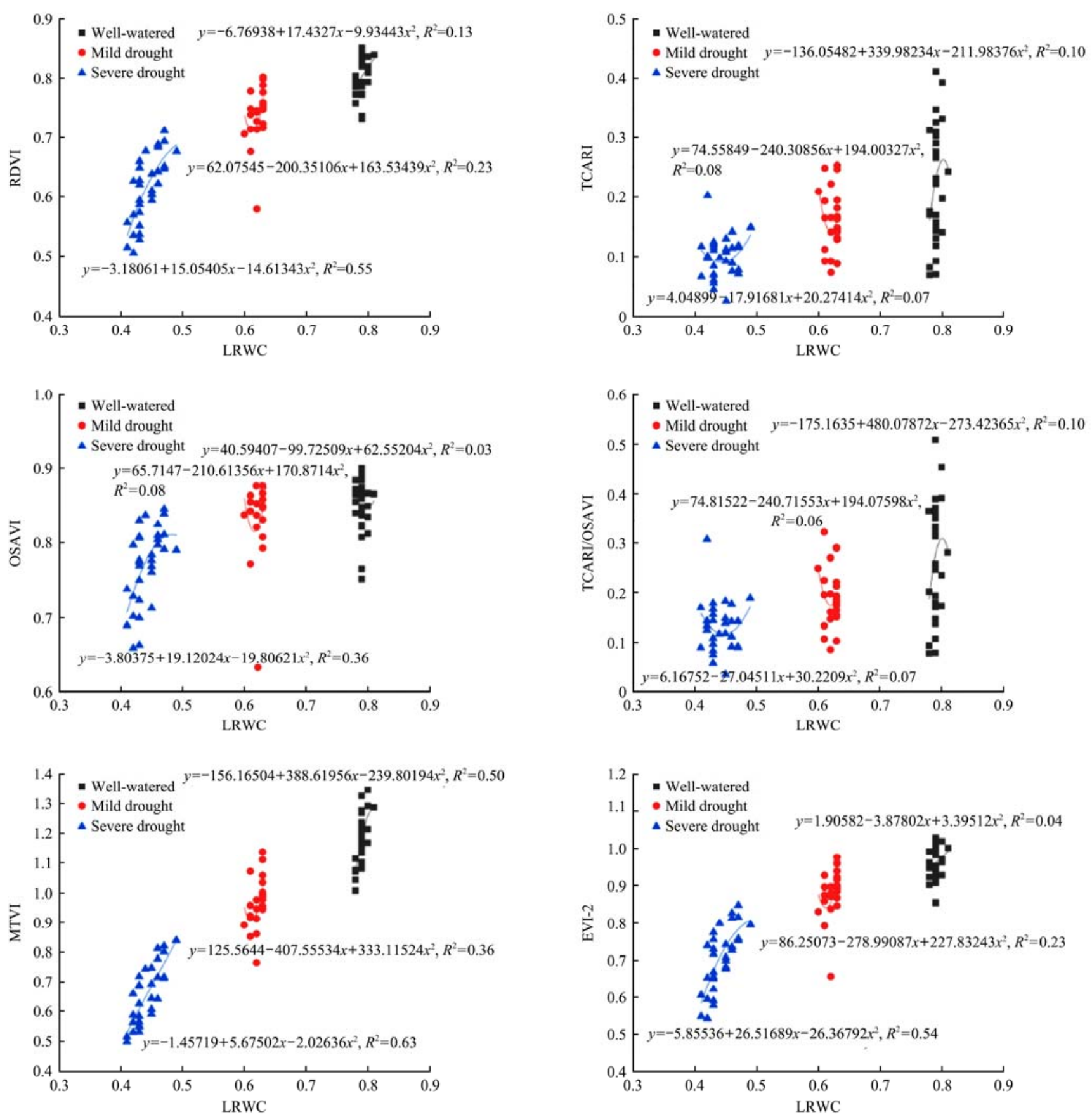

c. LRWC

Figure 4 Relationships between Fv/Fm (a), SPAD (b), LRWC (c) and multispectral indices based on canopy spectral reflectance in the VIS and NIR regions under well-watered, mild drought and severe drought stress treatment.

Data correspond to the two cultivars together for each drought stress treatment. $\quad N=31, R_{0.05}^{2}=0.36$

In order to test the above six sensitive indices for monitoring the soil water content in each drought stress, we analysis the relationship between the six indices and physiology parameters for each drought stress as showed in Figure $4(\mathrm{a}, \mathrm{b}, \mathrm{c})$. Based on $R^{2}$ values, only MTVI indices had significant curvilinear relationships with the three parameters under different drought stress. However, the TCARI and TCARI/OSAVI were not significantly related to the three parameters when the data of different drought stress were separated. Furthermore, regarding the relationships between the RDVI, OSAVI, EVI-2 and three parameters under different drought stress, it is noteworthy that significant relationships was showed only under severe drought stress, but not significant under well-watered and mild drought stress, which means that the three indices can monitor the water stress of peanut under severe drought stress conditions. The reason may be that the peanut cultivars might show different mechanism under different drought stress especially in the severe drought stress $^{[42]}$.

\section{Conclusions}

In our study, drought stress imposes significant effect on physiological parameters and canopy spectral reflectance of peanut plants. Higher relationships were found between the canopy spectral reflectance and the physiological parameters (SPAD, LRWC and $\mathrm{Fv} / \mathrm{Fm}$ ) which can be used to detect the leaf water status of the peanut plants under drought stress. Of the canopy spectral indices evaluated, MTVI was the only multispectral indices, which significant curvilinear relationships with the three parameters and can monitor the water status of peanut plants under 
different drought stress conditions and will be a successful method for water status monitoring that can assist farmers in timely irrigation. In our future work, experiments on more ecological locations and peanut cultivars should be conducted to evaluate the application of the MTVI indices for water status monitoring of peanut.

\section{Acknowledgement}

This research was funded by the Key Science and Technology Planning Project of Guangdong Province (2019B020214003), National Key R\&D Program of China (2018YFD1000906), and Guangdong Technical System of Peanut and Soybean Industry (2019KJ136-05).

\section{Conflicts of Interest}

The authors declare no conflict of interests.

\section{[References]}

[1] Varshney R K, Saxena R K, Upadhyaya H D, Khan A W, Yu Y, Kim C, Rathore A, Kim D, Kim J, An S, Kumar V, Anuradha G, Yamini K N, Zhang W, Muniswamy S, Kim J-S, Penmetsa R V, Wettberg E v, Datta S K. Whole-genome resequencing of 292 pigeonpea accessions identifies genomic regions associated with domestication and agronomic traits. Nature Genetics, 2017; 49: 1082-1088. doi.org/10.1038/ng.3872.

[2] FAOSTAT. Available: http://faostat.fao.org/. 2014.

[3] Akcay U C, Ercan O, Kavas M, Yildiz L, Yilmaz C, Oktem H A, Yucel M. Drought-induced oxidative damage and antioxidant responses in peanut (Arachishypogaea L.) seedlings. Plant Growth Regulation, 2010; 61: 21-28. doi.org/10.1007/s10725-010-9445-1.

[4] Knapp A K, Briggs J M, Koelliker J K. Frequency and extent of water limitation to primary production in a mesic temperate grassland. Ecosystems, 2001; 4: 19-28. doi.org/10.1007/s100210000057.

[5] Dai A. Increasing drought under global warming in observations and models. Nature climate change, 2013; 3: 52-58. doi.org/10.1038/ nclimate 1633.

[6] Guo R, Shi L, Jiao Y, Li M, Zhong X, Gu F, Liu Q, Xia X, Li H. Metabolic responses to drought stress in the tissues of drought-tolerant and drought-sensitive wheat genotype seedlings. AoB PLANTS, 2018; 10. doi: 10.1093/aobpla/ply016.

[7] Basu S, Ramegowda V, Kumar A, Pereira A. Plant adaptation to drought stress. F1000Research, 2016; 5:F1000 Faculty Rev-1554.

[8] Nanzad L, Zhang J, Tuvdendorj B, Nabil M, Zhang S, Bai Y. NDVI anomaly for drought monitoring and its correlation with climate factors over Mongolia from 2000 to 2016. Journal of Arid Environments, 2019; 164: 69-77. doi.org/10.1016/j.jaridenv.2019.01.019.

[9] Banks J M. Chlorophyll fluorescence as a tool to identify drought stress in Acer genotypes. Environmental and Experimental Botany, 2018; 155: 118-127. doi.org/10.1016/j.envexpbot.2018.06.022.

[10] Li R, Guo P, Michael B, Stefania G, Salvatore C. Evaluation of chlorophyll content and fluorescence parameters as indicators of drought tolerance in barley. Agricultural Sciences in China, 2006; 5: 751-757. doi.org/10.1016/S1671-2927(06)60120-X

[11] Egilla J N, Davies F T, Boutton T W. Drought stress influences leaf water content, photosynthesis, and water-use efficiency of Hibiscus rosa-sinensis at three potassium concentrations. Photosynthetica, 2005; 43: 135-140. doi.org/10.1007/s11099-005-5140-2.

[12] Zhou C, Le J, Hua D, He T, Mao J. Imaging analysis of chlorophyll fluorescence induction for monitoring plant water and nitrogen treatments. Measurement, 2019; 136: 478-486. doi.org/10.1016/j.measurement.2018. 12.088 .

[13] SalahvEl-Hendawy, Al-Suhaibani N, Hassan W, Tahir M, Schmidhalter U. Hyperspectral reflectance sensing to assess the growth and photosynthetic properties of wheat cultivars exposed to different irrigation rates in an irrigated arid region. PLoS One, 2017; 12:e0183262. doi.org/10.1371/ journal.pone.0183262.

[14] Li H, Dai S, Luo H. Status and prospects of agricultural drought monitoring. China Rural Technology, 2012; 5: 46-48. doi.org/10.1007/ s11442-016-1297-9.

[15] Kim Y, Glenn D M, Park J, Ngugi H, Lehman B, 2011. Hyperspectral image analysis for plant stress detection. American Society of Agricultural and Biological Engineers, 1009114. doi: 10.13031/ 2013.29814.

[16] Gamon J A, Peñuelas J, Field C B. A narrow-waveband spectral index that tracks diurnal changes in photosynthetic efficiency. Remote Sensing of Environment, 1992; 41: 35-44. doi.org/10.1016/0034-4257(92) 90059-S.

[17] Roujean J-L, Breon F-M. Estimating PAR absorbed by vegetation from bidirectional reflectance measurements. Remote Sensing of Environment, 1995; 51: 375-384. doi.org/10.1016/0034-4257(94)00114-3.

[18] Rouse J W, Haas R H, Schell J A, Deering D. Monitoring vegetation systems in the Great Plains with ERTS. In: Fraden, S.C., Marcanti, E.P., Becker, M. A. (Eds.), Third ERTS-1 Symposium, 10-14 Dec. 1973, NASA SP-351, Washington D.C.. NASA. 1974: 309-317.

[19] Haboudane D, Miller J R, Tremblay N, Zarco-Tejada P J, Dextraze L. Integrated narrow-band vegetation indices for prediction of crop chlorophyll content for application to precision agriculture. Remote Sensing of Environment, 2002; 81: 416-426. doi.org/10.1016/ S0034-4257(02)00018-4.

[20] Zhen Z, Chen S, Qin W, Li J, Mike M, Yang B. A modified transformed soil adjusted vegetation index for cropland in Jilin Province, China. Acta Geologica Sinica - English Edition, 2019; 93: 173-176.

[21] Mondal P. Quantifying surface gradients with a 2-band Enhanced Vegetation Index (EVI2). Ecological Indicators, 2011; 11: 918-924. doi.org/10.1016/j.ecolind.2010.10.006.

[22] Mishra A K, Singh V P. A review of drought concepts. Journal of Hydrology, 2010; 391: 202-216. doi.org/10.1016/j.jhydrol.2010.07.012.

[23] Barrs H, Weatherley P. A re-examination of the relative turgidity technique for estimating water deficits in leaves. Australian Journal of Biological Sciences, 1962; 15: 413-428. doi.org/10.1071/BI9620413.

[24] Chen T, Zeng R, Guo W, Hou X, Yubin Lan, Zhang L. Detection of stress in cotton (Gossypium hirsutum L.) caused by Aphids using leaf level hyperspectral measurements. Sensors (Basel), 2018; 18: 2798. doi.org/10.3390/s18092798.

[25] Rouse J W, Haas R H, Schell J A, Deering D W. Monitoring vegetation systems in the Great Plains with ERTS. Proceedings of the Earth Resources Technology Satellite Symposium NASA SP-351, Washington, DC, USA, 1973; 1: 309-317.

[26] Rougean J L, Breon F M. Estimating PAR absorbed by vegetation from bidirectional reflectance measurements. Remote Sensing of Environment, 1995; 51: 375-384. doi.org/10.1016/0034-4257(94)00114-3.

[27] Daughtry C S T, Walthall C L, Kim M S, Colstoun E B D, Iii J M. Estimating corn leaf chlorophyll concentration from leaf and canopy reflectance. Remote sensing of Environment, 2000; 74: 229-239. doi.org/10.1016/S0034-4257(00)00113-9.

[28] Wu C, Niu Z, Gao S. The potential of the satellite derived green chlorophyll index for estimating midday light use efficiency in maize, coniferous forest and grassland. Ecological Indicators, 2012; 14: 66-73. doi.org/10.1016/j.ecolind.2011.08.018.

[29] Penuelas J, Filella I, Lloret P, Munoz F, Vilajeliu M. Reflectance assessment of mite effects on apple trees. International Journal of Remote Sensing, 1995; 16: 2727-2733. doi.org/10.1080/01431169508954588.

[30] Gitelson A A, Viña A, Ciganda V, Rundquist D C, Arkebauer T J. Remote estimation of canopy chlorophyll content in crops. Geophysical Research Letters, 2005; 32: L08403. doi.org/10.1029/2005GL022688.

[31] Blackburn G A. Quantifying chlorophylls and caroteniods at leaf and canopy scales: an evaluation of some hyperspectral approaches. Remote Sensing of Environment, 1998; 66 273-285. doi.org/10.1016/ S0034-4257(98)00059-5.

[32] Gregory A Carter. Ratios of leaf reflectances in narrow wavebands as indicators of plant stress. International Journal of Remote Sensing, 1994; 15: 697-703. doi.org/10.1080/01431169408954109.

[33] Neto A J S, Lopes D d C, Silva T G F d, Ferreira S O, Grossi J A S. Estimation of leaf water content in sunflower under drought conditions by means of spectral reflectance. Engineering in Agriculture, Environment and Food, 2017; 10: 104-108. doi.org/10.1016/j.eaef.2016.11.006.

[34] Gonfa A, Tesfaye K, Geleto T. Morphological and physiological attributes associated to drought tolerance of Ethiopian durum whea genotypes under water deficit. Journal of Biodiversity and Environmental Sciences, 2011; 1: 22-36.

[35] Xu Q, Ma X, Lv T, Bai M, Wang Z, Niu J. Effects of water stress on fluorescence parameters and photosynthetic characteristics of drip irigation in rice. Water, 2020; $12: 289$. doi.org/10.3390/w12010289. 
[36] Levitt J. Responses of plants to environmental stresses. Volume II. Water, radiation, salt, and other stresses. Academic Press, 1980.

[37] Gutierrez M, Reynolds M P, Klatt A R. Association of water spectral indices with plant and soil water relations in contrasting wheat genotypes. Journal of Experimental Botany, 2010; 61: 3291-3303. doi.org/10.1093/ jxb/erq156.

[38] Ranjan R, Sahoo R N, Chopra U K, Pramanik M, Singh A K, Pradhan S. Assessment of water status in wheat (Triticum aestivum L.) using ground based hyperspectral reflectance. Proceedings of the National Academy of Sciences, India Section B: Biological Sciences, 2017; 87: 377-388. doi.org/10.1007/s40011-015-0618-6.

[39] Zygielbaum A I, Gitelson A A, Arkebauer T J, Rundquist D C. Non-destructive detection of water stress and estimation of relative water content in maize. Geophysical Research Letters, 2009; 36. doi.org/10.1029/2009GL038906.

[40] Lin C, Popescu S C, Huang S C, Chang P T, Wen H L. A novel reflectance-based model for evaluating chlorophyll concentrations of fresh and water-stressed leaves. Biogeosciences, 2015; 12: 49-66.

[41] Daughtry C S T, Walthall C L, Kim M S, Colstoun E B, McMurtrey J E. Estimating corn leaf chlorophyll concentration from leaf and canopy reflectance. Remote Sensing of Environment, 2000; 74: 229-239. doi.org/10.1016/S0034-4257(00)00113-9.

[42] Huang L, Zhang L, Zeng R, Wang X, Zhang H, Wang L, Liu S, Xuewen Wang, Chen T. Brassinosteroid priming improves peanut drought tolerance via eliminating inhibition on genes in photosynthesis and hormone signaling. Genes, 2020; 11: 919. doi.org/10.3390/genes11080919. 